\title{
BUDAYA ORGANISASI DAN KOMUNIKASI ORGANISASI: APAKAH ADA PENGARUHNYA TERHADAP PRESTASI KERJA USAHA KESEHATAN SEKOLAH?
}

\author{
Ipong Dekawati ${ }^{1}$, Wresni Pujiyati, ${ }^{2}$ Lingga $^{3}$ \\ 1,2,3 Universitas Wiralodra, Jln. Ir. H. Juanda Km 3 Indramayu, Jawa Barat, Indonesia, \\ ipongdekawati@unwir.ac.id, wresni.pujiyati@unwir.ac.id, lingga1111@gmail.com
}

Diterima 27 Februari 2020, disetujui 15 April 2020, diterbitkan 30 April 2020

Pengutipan: Dekawati, I, Pujiyati, W \& Lingga. (2020). Budaya organisasi dan komunikasi organisasi: apakah ada pengaruhnya terhadap prestasi kerja usaha kesehatan sekolah?.Gema Wiralodra, Vol 11, No 1, Hal 1-10, April 2020

\begin{abstract}
ABSTRAK
Kajian utama yang dijadikan masalah dalam penelitian ini adalah mengenai prestasi kerja Usaha Kesehatan Sekolah (UKS). Sedangkan tujuan penelitian ini yakni untuk mengetahui pengaruh budaya organisasi dan komunikasi organisasi terhadap prestasi kerja UKS. Desain penelitian ini menggunakan desain ex post facto dengan jenis causal correlation. Desain ini digunakan karena data mengenai prestasi kerja usaha kesehatan sekolah diambil setelah fakta terjadi. Sedangkan budaya dan komunikasi organisasi diambil dengan menggunakan angket. Partsipan yang terlibat dalam penelitian ini sebanyak 40 guru yang bertugas sebagai pembina UKS. Teknik analisis data yang digunakan yakni analisis korelasi dan regresi. Berdasarkan hasil analisis dapat disimpulkan: (1) terdapat pengaruh yang positif tetapi tidak signifikan budaya organisasi terhadap prestasi kerja UKS. (2) Terdapat pengaruh yang positif tetapi tidak signifikan komunikasi organisasi terhadap prestasi kerja UKS. (3) Terdapat pengaruh yang positif tetapi tidak signifikan budaya organisasi dan komunikasi organisasi secara simultan terhadap prestasi kerja UKS.

Kata Kunci: Budaya Organisasi, Komunikasi Organisasi dan Prestasi Kerja
\end{abstract}

\section{ABSTRACT}

The main study that is used as a problem in this research is the work performance of School Health Enterprises (UKS). While the purpose of this study is to determine the effect of organizational culture and organizational communication on UKS work performance. The design of this study used the ex post facto design with the type of causal correlation. This design was used because data on work performance of school health efforts were taken after the facts occurred. Whereas organizational culture and communication are taken by using a questionnaire. Participants involved in this study were 40 teachers who served as supervisors of UKS. Data analysis techniques used are correlation and regression analysis. Based on the results of the analysis it can be concluded: (1) there is a positive but not significant effect of organizational culture on UKS work performance. (2) There is a positive but not significant effect of organizational communication on UKS work performance. (3) There is a positive but not significant effect of organizational culture and organizational communication simultaneously on UKS work performance.

Keywords: Organizational Culture, Organizational Communication and Job Performance

\section{PENDAHULUAN}

Salah satu indiktor keberhasilan seseorang dilihat dari prestasi kerja. Prestasi kerja merupakan suatu hasil yang dicapai seseorang setelah melaksanakan tugas-tugas yang

Diterbitkan oleh:

Universitas Wiralodra

Jln. Ir. H. Juanda Km 3 Indramayu, Jawa Barat 
dibebankan kepadanya yang didasarkan atas kecakapan pengalaman, dan kesungguhan serta waktu (Hasibuan, 2010). Sedangkan menurut Sutrisno (2009), prestasi kerja adalah sebagai hasil kerja yang telah dicapai seseorang dari tingkah laku kerjanya dalam melaksanakan aktivitas kerja.

Faktor-faktor individu yang dimaksud adalah: 1) Usaha (effort) yang menunjukkan sejumlah sinergi fisik dan mental yang digunakan dalam menyelenggarakan gerakan tugas. 2) Abilities, yaitu sifat-sifat personal yang diperlukan untuk melaksanakan suatu tugas. 3) Role atau task perception, yaitu segala perilaku dan aktivitas yang dirasa perlu oleh individu untuk menyelesaikan suatu pekerjaan. Adapun faktor-faktor lingkungan yang mempengaruhi prestasi kerja adalah: a) Kondisi fisik. b) Peralatan. c) Waktu. d) Material. e) Pendidikan. f) Supervisi. g) Desain organisasi. h) Pelatihan. i) Keberunngan (Sutrisno, 2009). Oleh karena itu, fokus penelitian ini berkaitan dengan prestasi kerja UKS.

Berdasarkan hasil penelitian banyak sekali faktor yang mempengaruhi prestasi kerja, khususnya prestasi kerja UKS. Seperti penelitiannya Ervina, Tahlil \& Mulyadi (2018) menjelaskan bahwa hambatan dalam pelaksanaan UKS mencakup kurang optimalnya kerjasama antar sektoral, kurangnya tenaga terlatih, beban kerja yang tinggi, serta dampak issue kesehatan yang bertentangan sehingga menyebabkan berbagai kegiatan UKS menjadi terhambat dalam pelaksanaannya. Lebih lanjut Ervina, Tahlil \& Mulyadi (2018) menjelaskan bahwa peran Dinas Kesehatan dapat lebih optimal dan aktif dalam pelaksanaan program UKS secara rutin dan berkesinambungan, melakukan monitoring evaluasi terhadap program serta meningkatkan kerjasama lintas sektoral. Selain itu menurut Susana (2018) berdasarkan hasil penelitian merekomendasikan model hipotetik manajemen usaha kesehatan bagi peserta didik di Sekolah Dasar.

Hal berbeda disampaikan oleh Nurhana, Chrisnawati \& Labertus (2018) Pengetahuan, sikap, SDM dan sarana maupun prasarana merupakan faktor yang paling dominan dalam mendukung pelaksanaan UKS. Sedangkan Linati, Bhima, \& Dhanardhono (2016) menjelaskan bahwa tingkat pendidikan kesehatan siswa, pelayanan kesehatan sekolah, lingkungan sekolah, ketenagaan uks, fasilitas kesehatan sekolah, dukungan orang tua murid, sumber dana UKS, evaluasi dan pelaporan kasus kekerasan merupakan faktor yang mempengaruhi peran UKS dalam pencegahan perilaku kekerasan anak sekolah pada

Diterbitkan oleh: 
sekolah menengah Atas dan Kejuruan di Kota Semarang. Selain itu Candrawati \& Widiani (2015) menyimpulkan bahwa semakin baik Pelaksanaan Program UKS di sekolah, maka PHBS siswa akan menjadi lebih baik. Oleh karena itu Candrawati \& Widiani (2015) disarankan untuk melakukan penelitihan lebih lanjut dengan memperluas variabel lain yang dapat mempengaruhi PHBS siswa seperti faktor kesadaran siswa dan pengetahuan.

Berdasarkan penelitian-penelitian tersebut dijelaskan bahwa keberhasilan pelaksanaan UKS sangat dipengaruhi oleh faktor siswa, pelayananan dan faktor luar. Namun masih sedikit melihat faktor budaya organisasi dan komunikasi organisasi para pembinanya. Oleh sebab itu, penelitian ini bertujuan untuk melihat pengaruh dari budaya dan komunikasi organisasi terhadap prestasi UKS.

\section{METODOLOGI PENELITIAN}

Penelitian ini merupakan penelitian ex post facto. Variabel dependen dalam penelitian ini yakni prestasi kerja UKS. Untuk melihat prestasi kerja diambil dari data kinerja pengelolaan UKS oleh dinas kesehatan. Sedangkan untuk variabel bebasnya yakni budaya organisasi dan komunikasi organisasi yang diukur menggunakan angket. Populasi dalam penelitian ini adalah seluruh Anggota Tim Pembina Usaha Kesehatan Sekolah (UKS) Kabupaten Indramayu yang berjumlah 40 orang. Mengacu pada pendapat menurut Arikunto (2008:116) bahwa "penentuan pengambilan sampel sebagai berikut: Apabila kurang dari 100 lebih baik diambil semua hingga penelitiannya merupakan penelitian populasi. Sehingga, sampel dalam penelitian ini berjumlah 40 orang. Selain itu, analisis data yang digunakan dalam penelitian ini yakni analisis korelasi dan analisis regresi.

\section{HASIL PENELITIAN DAN PEMBAHASAN}

\section{Hasil Penelitian}

Berdasarkan hasil penelitian, ada tiga hasil yang diperoleh yakni (1) pengaruh budaya organisasi terhadap prestasi UKS; (2) Pengaruh komunikasi organisasi terhadap prestasi UKS dan (3) pengaruh budaya dan komunikasi organisasi secara simultan terhadap prestasi UKS. Untuk mengetahui besaran pengaruh budaya organisasi (X1) secara individual (parsial) terhadap prestasi kerja UKS (Y) dapat dilihat dari nilai t pada tabel

Diterbitkan oleh:

Universitas Wiralodra

Jln. Ir. H. Juanda Km 3 Indramayu, Jawa Barat 
Coefficients. Kriteria pengujian jika tingkat signifikansi lebih kecil dari 0.05 , maka hipotesis diterima. Adapun hasil pengujian hipotesis tersebut adalah sebagai berikut:

Tabel 1 Uji Hipotesis (t) Variabel $X_{1}$ terhadap $Y$

Coefficients $^{\text {a }}$

\begin{tabular}{|c|c|c|c|c|c|}
\hline \multirow[b]{2}{*}{ Model } & \multicolumn{2}{|c|}{$\begin{array}{l}\text { Unstandardized } \\
\text { Coefficients }\end{array}$} & $\begin{array}{l}\text { Standardized } \\
\text { Coefficients }\end{array}$ & & \\
\hline & $\mathrm{B}$ & $\begin{array}{l}\text { Std. } \\
\text { Error }\end{array}$ & Beta & & sig. \\
\hline (Constant) & 107,409 & 14,796 & & 259 &, 000 \\
\hline Budaya_Organisasi_x1 &,- 223 &, 176 &,- 202 & 1,272 & ,211 \\
\hline
\end{tabular}

a. Dependent Variable: Prestasi_Kerja_Y

Berdasarkan tabel hasil uji $\mathrm{t}$ diperoleh bahwa nilai thitung variabel budaya organisasi $\left(\mathrm{X}_{1}\right)$ memiliki nilai sebesar p-value $0,000<0,05$ artinya berdistribusi signifikan. Hal tersebut berarti budaya organisasi $\left(\mathrm{X}_{1}\right)$ secara parsial berpengaruh terhadap prestasi kerja UKS (Y). Hal tersebut berarti menerima hipotesis yang menyatakan: "Terdapat pengaruh positif dan signifikan budaya organisasi terhadap prestasi kerja UKS di Kabupaten Indramayu ". Persamaan regresi $\widehat{y}=\mathrm{a} b X_{1}$ dari hasil perhitungan diperoleh $\hat{y}=$ $107,409+0,223 X_{1}$. Konstanta sebesar 107,409 menyatakan bahwa jika ada kenaikan nilai dari variabel budaya organisasi $\left(\mathrm{X}_{1}\right)$, maka prestasi kerja UKS (Y) adalah 107,409. Koefesien regresi sebesar 0,223 menyatakan bahwa setiap perubahan satu skor atau nilai budaya organisasi akan memberikan skor 0,223.

\section{Tabel 2 Uji Hipotesis (t) Variabel $X_{2}$ terhadap Y}

\begin{tabular}{|c|c|c|c|c|c|c|}
\hline & \multicolumn{6}{|c|}{ Coefficients $^{\mathrm{a}}$} \\
\hline & \multirow[b]{2}{*}{ Model } & \multicolumn{2}{|c|}{$\begin{array}{c}\text { Unstandardized } \\
\text { Coefficients }\end{array}$} & $\begin{array}{l}\text { Standardized } \\
\text { Coefficients }\end{array}$ & & \multirow[b]{2}{*}{ sig. } \\
\hline & & B & Std. Error & Beta & & \\
\hline \multirow[t]{2}{*}{1} & (Constant) & 80,446 & 11,424 & & 7,042 &, 000 \\
\hline & $\begin{array}{l}\text { Komunikasi_Organisasi_X } \\
2\end{array}$ &, 095 & ,133 & ,115 &, 715 & ,479 \\
\hline
\end{tabular}

a. Dependent Variable: Prestasi_Kerja_Y

Berdasarkan tabel hasil uji t diperoleh bahwa nilai thitung variabel komunikasi organisasi (X2) memiliki nilai sebesar p-value 0,000 $<0,05$ artinya signifikan. Dengan demikian komunikasi organisasi (X2) secara parsial berpengaruh terhadap prestasi kerja UKS (Y). Hal tersebut mengandung makna diterimanya hipotesis yang menyatakan:

Diterbitkan oleh:

Universitas Wiralodra

Jln. Ir. H. Juanda Km 3 Indramayu, Jawa Barat 
“Terdapat pengaruh positif dan signifikan komunikasi organisasi terhadap prestasi kerja UKS di Kabupaten Indramayu ". Persamaan regresi diperoleh $\hat{y}=\mathrm{a} \mathrm{bx}_{2}$ dari hasil perhitungan diperoleh $\hat{y}=80,446+0,095 \mathrm{X}_{2}$. Konstanta sebesar 80,446 menyatakan bahwa jika ada kenaikan nilai dari variabel komunikasi organisasi $\left(\mathrm{X}_{2}\right)$, prestasi kerja UKS (Y) adalah 80,446. Koefesien regresi sebesar 0,095 menyatakan bahwa setiap perubahan satu skor atau komunikasi organisasi akan memberikan skor 0,095.

Untuk mengetahui besaran pengaruh budaya organisasi (X1) dan komunikasi organisasi secara bersama-sama (ganda) terhadap prestasi kerja UKS (Y) dapat dilihat dari nilai $\mathrm{t}$ pada tabel Coefficients dibawah ini dengan kriteria pengujian jika tingkat signifikansi lebih kecil dari 0,05, maka hipotesis diterima. Adapun hasil pengujian hipotesis tersebut adalah sebagai berikut:

\section{Tabel 3 Uji Hipotesis ( $t$ ) Variabel $X_{1}$ dan $X_{2}$ terhadap $Y$}

\begin{tabular}{|c|c|c|c|c|c|c|}
\hline \multicolumn{7}{|c|}{ Coefficients $^{\mathrm{a}}$} \\
\hline \multirow{2}{*}{\multicolumn{2}{|c|}{ Model }} & \multicolumn{2}{|c|}{$\begin{array}{c}\text { Unstandardized } \\
\text { Coefficients }\end{array}$} & $\begin{array}{r}\text { Standardized } \\
\text { Coefficients } \\
\end{array}$ & & sig. \\
\hline & & B & Std. Error & Beta & & \\
\hline \multirow[t]{3}{*}{1} & (Constant) & 99,280 & 16,075 & & 176 &, 000 \\
\hline & Budaya_Organisasi_x1 &,- 303 & ,186 &,- 274 & 1,631 &, 111 \\
\hline & Komunikasi_Organisasi_X2 &, 173 & ,139 & ,209 &, 245 & ,221 \\
\hline
\end{tabular}

a. Dependent Variable: Prestasi_Kerja_Y

Berdasarkan tabel hasil uji t diperoleh bahwa nilai thitung variabel budaya organisasi $\left(\mathrm{X}_{1}\right)$ dan komunikasi organisasi $\left(\mathrm{X}_{2}\right)$ secara bersama-sama (simultan) memiliki nilai sebesar $\mathrm{p}$-value $0,000<0,05$ artinya signifikan. Dengan demikian budaya organisasi $\left(\mathrm{X}_{1}\right)$ dan komunikasi organisasi $\left(\mathrm{X}_{2}\right)$ secara bersama-sama (simultan) berpengaruh terhadap prestasi kerja UKS (Y). Hal tersebut membuktikan diterimanya hipotesis yang menyatakan: "Terdapat pengaruh positif dan signifikan budaya organisasi dan komunikasi organisasi secara bersama-sama terhadap prestasi kerja UKS di Kabupaten Indramayu ”.

\section{Pembahasan}

Pertama, permasalahan yang ingin dijawab dalam penelitian ini adalah adakah pengaruh budaya organisasi terhadap prestasi kerja UKS di Kabupaten Indramayu. Secara empirik, hasil penelitian ini menginformasikan: (1) terdapat pengaruh positif yang tidak

Diterbitkan oleh: 
signifikan antara budaya organisasi terhadap prestasi kerja UKS di Kabupaten Indramayu, serta (2) besarnya kontribusi budaya organisasi terhadap prestasi kerja UKS di Kabupaten Indramayu ditunjukkan oleh hasil penelitian bahwa budaya organisasi yang terdiri dari dimensi: (1) Inovasi dan Pengambilan resiko; (2) Stabilitas dan Keamanan; (3) Penghargaan kepada Orang; (4) Orientasi Hasil; (5) Orientasi TIM dan Kolaborasi; (6) Keagresifan dan persaingan (O’Relly, dkk. dalam Munandar, 2001:267), membawa implikasi yang signifikan terhadap prestasi kerja UKS dengan dimensi: (1) Hasil Kerja secara Kualitas; (2) Hasil Kerja secara Kuantitas; (3) Tingkah Laku Kerja; (4) Melaksanakan Tugas; (5) Tanggung jawab (Mangkunegara, 2009:67) dan (Sutrisno, 2009:151).

Namun demikian prestasi kerja UKS tidak hanya dipengaruhi oleh budaya organisasi saja, ada faktor lain (epsilon), selain dari komunikasi organisasi, yang juga berpengaruh, yang tidak dikaji dalam penelitian ini. Dengan demikian, hasil penelitian ini mengindikasikan bahwa semakin bagus budaya organisasi pada UKS, maka akan diikuti oleh semakin tingginya prestasi kerja UKS. Hal ini dapat diterangkan oleh persamaan regresi $\widehat{y}=107,409+0,223 \mathrm{X}_{1}$. Dengan persamaan regresi tersebut dapat diinterpretasikan bahwa jika budaya organisasi $\left(\mathrm{X}_{1}\right)$ dengan prestasi kerja UKS (Y) diukur dengan instrumen yang dikembangkan dalam penelitian ini, maka setiap perubahan skor budaya organisasi sebesar satu satuan dapat diestimasikan skor prestasi kerja UKS akan berubah 0,223 satuan pada arah yang sama.

Berdasarkan temuan empirik yang menunjukkan adanya pengaruh yang signifikan budaya organisasi terhadap prestasi kerja UKS, maka hasil penelitian ini memberikan beberapa informasi, diantaranya: (1) Budaya organisasi pada UKS di Kabupaten Indramayu memberikan kontribusi yang berarti terhadap prestasi kerja UKS, (2) Salah satu cara untuk meningkatkan prestasi kerja UKS di Kabupaten Indramayu adalah dengan meningkatkan budaya organisasi, serta (3) Persentase kontribusi budaya organisasi terhadap prestasi kerja UKS adalah sebesar 4,1\%, sementara sisanya dipengaruhi oleh variabel lain, selain variabel komunikasi organisasi, yang tidak dikaji dalam penelitian ini (epsilon). Kedua, permasalahan yang ingin dijawab dalam penelitian ini adalah adakah pengaruh komunikasi organisasi terhadap prestasi kerja UKS di

Diterbitkan oleh: 
Kabupaten Indramayu. Secara empirik, hasil penelitian ini menginformasikan: (1) terdapat pengaruh positif yang tidak signifikan antara komunikasi organisasi terhadap prestasi kerja UKS di Kabupaten Indramayu, serta (2) besarnya kontribusi komunikasi organisasi terhadap prestasi kerja UKS di Kabupaten Indramayu ditunjukkan oleh hasil penelitian bahwa komunikasi organisasi yang terdiri dari dimensi: (1) Informasi; (2) Gagasan; (3) Fakta; (4) Pikiran; (5) Perasaan (Hariandja, 2009:296), membawa implikasi yang signifikan terhadap prestasi kerja UKS dengan dimensi: (1) Hasil Kerja secara Kualitas; (2) Hasil Kerja secara Kuantitas; (3) Tingkah Laku Kerja; (4) Melaksanakan Tugas; (5) Tanggung jawab (Mangkunegara, 2009:67) dan (Sutrisno, 2009:151) dengan demikian, hasil penelitian ini mengindikasikan bahwa semakin baik komunikasi organisasi di Kabupaten Indramayu, maka akan diikuti oleh semakin tingginya prestasi kerja UKS. Hal ini dapat diterangkan oleh persamaan regresi $\widehat{y}=810,446+0,095 X 2$. Dengan persamaan regresi tersebut dapat diinterpretasikan bahwa jika komunikasi organisasi (X2) dan prestasi kerja UKS (Y) diukur dengan instrumen yang dikembangkan dalam penelitian ini, maka setiap perubahan skor komunikasi organisasi sebesar satu satuan dapat diestimasikan skor prestasi kerja UKS akan berubah 0,095 satuan pada arah yang sama.

Berdasarkan temuan empirik yang menunjukkan adanya pengaruh yang signifikan komunikasi organisasi terhadap prestasi kerja UKS, maka hasil penelitian ini memberikan beberapa informasi, di antaranya: (1) Komunikasi organisasi pada UKS di Kabupaten Indramayu memberikan kontribusi yang berarti terhadap prestasi kerja UKS; (2) Salah satu cara untuk meningkatkan prestasi kerja UKS di Kabupaten Indramayu adalah dengan meningkatkan komunikasi organisasi; serta (3) Persentase kontribusi komunikasi organisasi terhadap prestasi kerja UKS adalah sebesar 1,3\%, sementara sisanya dipengaruhi oleh variabel lain, selain variabel budaya organisasi, yang tidak dikaji dalam penelitian ini (epsilon).

Ketiga, Permasalahan yang ingin dijawab dalam penelitian ini adalah adakah pengaruh budaya organisasi, dan komunikasi organisasi terhadap prestasi kerja UKS di Kabupaten Indramayu. Secara empirik, hasil penelitian ini menginformasikan: (1) Terdapat pengaruh positif yang tidak signifikan antara budaya organisasi dan komunikasi organisasi secara bersama-sama terhadap prestasi kerja UKS di Kabupaten Indramayu, serta (2) Besarnya

Diterbitkan oleh:

Universitas Wiralodra

Jln. Ir. H. Juanda Km 3 Indramayu, Jawa Barat 
pengaruh budaya organisasi dan komunikasi organisasi terhadap prestasi kerja UKS di Kabupaten Indramayu ditunjukkan oleh hasil penelitian bahwa budaya organisasi yang terdiri dari dimensi: (1) Inovasi dan Pengambilan resiko; (2) Stabilitas dan Keamanan; (3) Penghargaan kepada Orang; (4) Orientasi Hasil; (5) Orientasi TIM dan Kolaborasi; (6) Keagresifan dan persaingan (O’Relly, dkk. dalam Munandar, 2001:267), serta komunuikasi organisasi dengan dimensi: (1) Informasi; (2) Gagasan; (3) Fakta; (4) Pikiran; (5) Perasaan (Hariandja, 2009:296), membawa implikasi yang signifikan terhadap prestasi kerja UKS dengan dimensi: (1) Hasil Kerja secara Kualitas; (2) Hasil Kerja secara Kuantitas; (3) Tingkah Laku Kerja; (4) Melaksanakan Tugas; (5) Tanggung jawab (Mangkunegara, 2009:67) dan (Sutrisno, 2009:151). Namun demikian prestasi kerja UKS di Kabupaten Indramayu ini tidak hanya dipengaruhi oleh budaya organisasi, dan komunikasi organisasi saja, ada faktor lain (epsilon), yang juga berpengaruh, yang tidak dikaji dalam penelitian ini. Dengan demikian, hasil penelitian ini mengindikasikan bahwa semakin baik budaya organisasi, dan semakin tinggi komunikasi organisasi pada UKS di Kabupaten Indramayu, maka akan diikuti oleh semakin tingginya prestasi kerja UKS. Hal ini dapat diterangkan oleh persamaan regresi: $\widehat{y}=99,280+0,303 X_{1}+0,173 X_{2}$. Dengan persamaan regresi tersebut dapat diinterpretasikan bahwa jika budaya organisasi $\left(\mathrm{X}_{1}\right)$, dan komunikasi organisasi $\left(\mathrm{X}_{2}\right)$ dengan prestasi kerja UKS $(\mathrm{Y})$ diukur dengan instrumen yang dikembangkan dalam penelitian ini, maka setiap perubahan skor budaya organisasi dan komunikasi organisasi sebesar satu satuan dapat diestimasikan skor prestasi kerja UKS akan berubah 0,303 dan 0,173 satuan pada arah yang sama.

Berdasarkan temuan empirik yang menunjukkan adanya pengaruh yang tidak signifikan budaya organisasi, dan komunikasi organisasi terhadap prestasi kerja UKS, maka hasil penelitian ini memberikan beberapa informasi, di antaranya: (1) Budaya organisasi, dan komunikasi organisasi pada UKS di Kabupaten Indramayu memberikan kontribusi yang berarti terhadap prestasi kerja UKS; (2) Salah satu cara untuk meningkatkan prestasi kerja UKS di Kabupaten Indramayu adalah dengan meningkatkan budaya organisasi dan komunikasi organisasi; (3) Persentase kontribusi yang diberikan oleh budaya organisasi dan komunikasi organisasi secara bersama-sama terhadap prestasi

Diterbitkan oleh:

Universitas Wiralodra

Jln. Ir. H. Juanda Km 3 Indramayu, Jawa Barat 
kerja UKS adalah sebesar $7,9 \%$, sementara sisanya dipengaruhi faktor lain yang tidak dibahas dalam penelitian ini (epsilon).

\section{KESIMPULAN}

Berdasarkan permasalahan yang telah dirumuskan serta hasil penelitian dan pembahasan, maka dapat dikemukakan beberapa kesimpulan sebagai berikut:

1) Terdapat pengaruh yang positif tetapi tidak signifikan budaya organisasi terhadap prestasi kerja UKS di Kabupaten Indramayu. Besarnya pengaruh budaya organisasi terhadap prestasi kerja UKS di Kabupaten Indramayu adalah 4,1 \%, sementara sisanya dipengaruhi oleh variabel lain, selain variabel komunikasi organisasi, yang tidak dikaji dalam penelitian ini.

2) Terdapat pengaruh yang positif tetapi tidak signifikan komunikasi organisasi terhadap prestasi kerja UKS di Kabupaten Indramayu. Besarnya pengaruh komunikasi organisasi terhadap prestasi kerja UKS di Kabupaten Indramayu adalah 1,3\%, sementara sisanya dipengaruhi oleh variabel lain, selain variabel budaya organisasi, yang tidak dikaji dalam penelitian ini.

3) Terdapat pengaruh yang positif tetapi tidak signifikan budaya organisasi dan komunikasi organisasi secara simultan terhadap prestasi kerja UKS di Kabupaten Indramayu. Besarnya pengaruh budaya organisasi dan komunikasi organisasi secara simultan terhadap prestasi kerja UKS di Kabupaten Indramayu adalah 7,9 \%, sementara sisanya dipengaruhi faktor lain yang tidak dibahas dalam penelitian ini (epsilon).

\section{DAFTAR PUSTAKA}

Arikunto, S. (2008). Prosedur Penelitian Suatu Pendekatan Praktik. Jakarta: Rineka Karya.

Candrawati, E., \& Widiani, E. (2015). Pelaksanaan Program UKS dengan Perilaku Hidup Bersih dan Sehat (PHBS) Siswa Sekolah Dasar di Kecamatan Kedung Kandang Kota Malang. Care: Jurnal Ilmiah Ilmu Kesehatan, Vol 3, No 1, Hal 15-23.

Ervina, E., Tahlil, T., \& Mulyadi, M. (2018). Pelaksanaan Program Usaha Kesehatan Sekolah (UKS) Di Puskesmas. Jurnal Ilmu Keperawatan, Vol 6, No 2, Hal 11-21.

Hasibuan, M.S.P (2010). Manajemen Sumber Daya Manusia. Jakarta: Bumi Akrasa.

Diterbitkan oleh:

Universitas Wiralodra

Jln. Ir. H. Juanda Km 3 Indramayu, Jawa Barat 
Hariandja, E. (2010) Manajemen Sumber Daya Manusia. Jakarta: Grasindo.

Linati, F. M. D., Bhima, S. K. L., \& Dhanardhono, T. (2016). Faktor-Faktor Yang Mempengaruhi Peran Usaha Kesehatan Sekolah Terhadap Pencegahan Perilaku Kekerasan Anak Sekolah Pada Sekolah Menengah Atas dan Kejuruan (Doctoral dissertation, Diponegoro University).

Mangkunegara, A.P. (2009). Manajemen Sumber Daya Manusia Perusahaan, Bandung: Remaja Rosda Karya.

Munandar, A, S. (2008). Psikologi Industri dan Organisasi. Jakarta: Universitas Indonesia (UI-Press).

Nurhana, L. E., Chrisnawati, C., \& Labertus, K. (2018). Faktor-Faktor Pendukung Pelaksanaan Usaha Kesehatan Sekolah (UKS) di Tingkat Sekolah Dasar. Jurnal Keperawatan Suaka Insan (JKSI), Vol 3, No 2, Hal 1-7.

Susana, A. (2018). Manajemen Kesehatan Peserta Didik Sekolah Dasar. Jurnal Administrasi Pendidikan, Vol 25, No 1, Hal 65-79.

Sutrisno, E. (2009). Manajemen Sumber Daya Manusia, Edisi Pertama. Jakarta: Kencana. 